\title{
Escolarização de alunos com deficiência no Brasil: uma análise sob a perspectiva dos estudos de Lev Vygotsky
}

\author{
Schooling of students with disabilities in Brazil: approaches with Lev Vygotsky
} studies

Francélio Ângelo de Oliveira Adriana Leite Limaverde Gomes

\begin{abstract}
Resumo: Objetiva-se investigar o processo de escolarização de pessoas com deficiência no Brasil, aproximando tal fenômeno a alguns pressupostos teóricos da obra de Lev Vygotsky, sobretudo aos escritos dispostos nos Fundamentos de defectologia. Trata-se de um estudo bibliográfico, em que se buscou compreender os processos históricos de escolarização das pessoas com deficiência no Brasil, a fim de contribuir para uma análise da atual conjuntura que atravessa a problemática da inclusão escolar nos sistemas de ensino. Os resultados apontaram para um processo histórico de segregação das pessoas com deficiência, que se manifestou de diferentes modos: privação no interior de instituições especializadas e submissão ao silenciamento e ao abandono. Com base nos estudos da defectologia, que consideram o desenvolvimento humano na e pela coletividade, destacou-se a relevância da inclusão escolar, visto que o processo de humanização ocorre por meio da apropriação cultural. Frente a essa perspectiva, conclui-se que a escola ganha destaque como um espaço privilegiado para a transmissão dos saberes historicamente sistematizados pela humanidade $\mathrm{e}$, consequentemente, por sua contribuição ao processo de desenvolvimento e humanização dos indivíduos.
\end{abstract}

Palavras-chave: Institucionalização, Alunos com deficiência, Inclusão escolar.

\begin{abstract}
The objective is to investigate the schooling process of people with disabilities in Brazil, bringing this phenomenon closer to some theoretical assumptions of Lev Vygotsky's work, especially to the writings in the Fundamentals of Defectology. This is a bibliographic study, in which we sought to understand the historical processes of schooling for people with disabilities in Brazil, in order to contribute to an analysis of the current situation that crosses the issue of school inclusion in education systems. The results pointed to a historical process of segregation of people with disabilities, which manifested itself in different ways: deprivation within specialized institutions and submission to silence and abandonment. Based on studies of defectology, which consider human development in and by the community, the relevance of school inclusion was highlighted, since the humanization process occurs through cultural appropriation. In view of this perspective, it is concluded that the school is highlighted as a privileged space for the transmission of knowledge historically systematized by humanity and, consequently, for its contribution to the process of development and humanization of individuals.
\end{abstract}

Keyword: Institutionalization, Students with disabilities, School inclusion. 


\section{Introdução}

Este ensaio propõe discutir o processo de escolarização de alunos com deficiência, considerando o modo como o sistema educacional brasileiro vem se relacionando historicamente com esses indivíduos. Quanto aos aspectos metodológicos, trata-se de uma pesquisa bibliográfica embasada nos estudos de autores que integram a chamada Psicologia histórico-cultural soviética, dentre os quais destacamos Vygotsky (1983). Nessa mesma perspectiva, recorremos a Baquero (1998) e a Marques et al. (2009), que nos apoiaram na clarificação desses pressupostos teóricos. No que concerne aos aspectos históricos, destacamos Jannuzzi (1992), por trazer um panorama sobre a história da educação de pessoas com deficiência no Brasil.

O debate sobre a inclusão escolar é necessário, pois suscita a reflexão sobre os processos de exclusão aos quais são submetidos os alunos que não se enquadram nos padrões normativos impostos pelos sistemas educacionais. A massificação dos processos de ensino e a imposição de tempos, ritmos e estilos de aprendizagem são fatores excludentes no interior da sala de aula. Urge, portanto, a ruptura desse modelo escolar segregador rumo à construção de uma escola, de fato, para todos.

Apesar da existência dos chamados marcos legais da educação especial inclusiva no Brasil, dentre os quais podemos citar a Política Nacional da Educação Especial na Perspectiva da Educação Inclusiva (2008) e da conhecida Lei Brasileira de Inclusão das Pessoas com Deficiência (2015), o processo de escolarização dos alunos público-alvo da educação especial permanece como um desafio aos sistemas de ensino.

Para a compreensão de tais desafios ao processo de escolarização, sobretudo dos discentes com deficiência, é necessário atentarmos para as bases históricas sobre as quais se ergue o sistema educacional brasileiro. De acordo com a perspectiva de Piletti, N. e Piletti, C. (1990), a educação brasileira é historicamente dual, portanto se poderia falar de "educações", uma vez que as condições de escolarização não são iguais para todos.

Mesmo a sistematização do ensino no Brasil Colônia tendo sido endereçada tanto aos indígenas quanto aos filhos dos colonos, na prática 
houve um distanciamento entre esses dois grupos, especialmente no que tange às finalidades do processo de escolarização a que eles foram submetidos. De acordo com Ribeiro (1981, p. 29), “[...] o plano legal (catequizar e instruir os índios) e o plano real se distanciaram. Os instruídos serão descendentes dos colonizadores. Os indígenas serão apenas catequizados".

Assim, a história da educação brasileira se constitui sob um processo de segregação e privilégios - segregação destinada aos grupos historicamente marginalizados e privilégios destinados à elite dirigente, na qual se concentraram os esforços no sentido de garantir o acesso e a qualidade da educação escolar. Como exemplos desses grupos não hegemônicos, podemos destacar a população negra, as mulheres e as pessoas com deficiência.

No que concerne à história da educação especial no Brasil, podemos constatar que as pessoas com deficiência foram marginalizadas em função do padrão de normalidade que se convencionou historicamente e que se materializou em diferentes espaços geográficos e culturais.

$\mathrm{Na}$ sociedade de consumo, é incessante a luta pela padronização do homem por parte das forças produtivas, isso porque os bens produzidos e comercializados buscam atingir um perfil de consumidor. Assim, é necessário que as características individuais cedam lugar a um determinado modelo de sociedade para que a produção em série atinja maiores índices.

A padronização do ser humano é buscada em várias dimensões, que vão desde o tipo físico até as características psicológicas, gostos, gestos, preferências, desejos, etc. É preciso, pois, desejar para comprar, pensar a existência da necessidade para consumir, daí a importância de se estabelecer um perfil uniforme de consumidor. É nesse contexto de "mercadorização" do ser humano que a escola se insere, por isso não há neutralidade na instituição escolar. Ela reproduz e reafirma a lógica do sistema no qual está inserida, buscando, desse modo, uniformizar o aluno para atender às demandas das forças produtivas, bem como perpetuar a estrutura de poder existente.

Nessa conjuntura, encontram-se inseridos os alunos com deficiência e com outras tantas diferenças. Instaura-se, portanto, uma relação conflituosa, pois aqueles que não conseguem se inserir no padrão normatizado são vistos 
como "corpos estranhos" dentro de uma engrenagem que necessita de um padrão para mover-se. Assim, objetivamos, a partir deste artigo, estudar brevemente o processo de escolarização de pessoas com deficiência no Brasil, aproximando tal fenômeno a alguns pressupostos teóricos presentes na obra de Lev Vygotsky, isso porque a educação escolar se constitui como instrumento a partir do qual os indivíduos são instrumentalizados para uma participação social mais efetiva.

As instituições especializadas se inserem nessa lógica uniformizante, na tentativa de normalizar o sujeito, ou seja, aproximá-lo ao máximo dos ditames socioeconômicos. Nessa perspectiva, quanto mais próximo do "normal" ela conseguir enquadrar o educando, maior é a sua "eficácia" frente às expectativas da sociedade.

Norteada pelos princípios fundamentais de normalização e integração, a educação especial, por meio de suas instituições, mantém esses indivíduos sob seus domínios, na tentativa de, através de seus programas especiais, garantir uma certa simetria entre o que a sociedade tem como padrão de normalidade e a maciça expressividade do indivíduo que diverge. (TOMASINI Apud BIANCHETTI \& FREIRE, 1998, p. 126).

Assim, as instituições se centram em patologias e são imersas no olhar social, que projeta na pessoa a responsabilidade de sobressair-se em um mundo competitivo. Nesse sentido, elas encontram espaço na vida das pessoas com deficiência com a missão de prepará-las para sua inserção nos mais diferentes setores sociais, como nos mostra Tomasi (apud BIANCHETTI \& FREIRE,1998, p. 120):

A visão de patologias individuais e a centralização do problema somente no indivíduo, responsabilizando-o pela diferença que apresenta, vão dar vida a todo um aparato institucional especializado e segregado.

Por essa razão, esses espaços de segregação reforçam a exclusão e a inferiorização das pessoas, porque elas não se enquadram no padrão socialmente imposto, ou seja, não é possível homogeneizá-las, pois as diferenças sempre estarão presentes como condições do sujeito. Logo, essas 
pessoas ficarão à margem dos espaços sociais, acentuando, assim, a sensação de inferioridade e fracasso.

A permanência dessas instituições segregativas demonstra o quanto a sociedade é despreparada para lidar com as diferenças, ao tempo que também evidencia o quanto se discrimina em função do mercado voraz, que desconsidera as características individuais das pessoas.

O aumento maciço de instituições especiais (escolas, hospitais, prisões, manicômios) não representa necessariamente a abertura do mercado para os economicamente ativos e em funcionamento na sociedade e também a exposição clara de uma grande falha social (TOMASINI Apud BIANCHETTI \& FREIRE, 1998, p. 126).

Marques et al. (2009) apontam a necessidade de um novo modelo no que se refere à formação docente. As autoras justificam essa necessidade em virtude da prática docente estar reduzida a um padrão normalizador, em que se busca ajustar o educando aos padrões convencionais nos âmbitos físico, moral, intelectual, social e psicológico. Todos esses ajustes forçados reprimem as características individuais do educando, reduzindo a riqueza da heterogeneidade existente em sala de aula.

Partindo dessa lógica, os sujeitos com características que fogem ao padrão socialmente estabelecido são submetidos a sentenças que vão do extremo da separação até a comiseração. Esses sentimentos resultam nas práticas de enclausuramento em ambientes que restringem suas liberdades e os privam de desfrutarem dos variados ambientes sociais. Como exemplos disso, encontramos as instituições do tipo asilos, escolas especiais, hospitais psiquiátricos, entre outras.

Essas instituições segregadoras se revestem de um discurso assistencialista, cheio de "compaixão", que, além de privar a sociedade do convívio com as diferenças, visam enquadrar esses indivíduos dentro do modelo socialmente aceito. Nesse sentido, defendem o emprego de técnicas normalizadoras para deixá-las o mais parecidas possível com os ditames convencionais.

Numa sociedade midiática, o corpo é utilizado como uma estrutura de classificação e poder. Com a exibição de corpos esculturais, ditados e criados 
para atender a uma lógica de mercado, instala-se uma preocupação doentia e exacerbada por enquadrar-se dentro dos moldes impostos por inúmeras mídias. Nesse contexto:

\begin{abstract}
A presença ou a ausência de membros e sentidos do corpo, a tonalidade da pele, a textura do cabelo, a cor dos olhos, a gordura, a altura, enfim, um conjunto de elementos presentes no corpo são adotados como mecanismo de classificação dos sujeitos, determinando suas identidades, suas potencialidades e espaços de realização (MARQUES et al., 2009, p. 78).
\end{abstract}

A ideia de "lapidar" a pessoa, ou seja, torná-la o mais próxima possível os ditos normais, é posta em prática a partir do envio dos indivíduos socialmente desviantes às instituições especializadas. Nessas instituições, trabalha-se incansavelmente na busca por tornar esses sujeitos em seres sociáveis, minimamente aptos a se integrarem em alguns espaços sociais. "O simples fato de não ser o sujeito ideal, uma vez que se funde a ilusão de uma existência, faz do sujeito um ser desviante, desqualificado, e, portanto, tolerado, negociado, e quando possível, concertado" (MARQUES et al., 2009, p. 83).

Foucault (1999) e Marques et al. (2009) destacam os exames médicos como uma ferramenta utilizada para classificar e confinar indivíduos "desviantes". Uma vez expedido tal documento, a pessoa se torna legalmente estigmatizada por uma suposta condição patológica. Desse modo, o "desvio" passa a ser a principal referência para o atendimento e o acesso aos inúmeros serviços existentes na sociedade, justificando até mesmo o cerceamento e a restrição a inúmeros espaços sociais.

Sant'Ana (apud MARQUES et al., 2009) entende que os especialistas rotulam os indivíduos através de laudos, levando-os a serem vistos como incapazes, sem condições alguma de se autogerenciarem. Nesse sentido, eles ficam à mercê das instituições, que assumem a tutela sobre suas vidas, tirando-Ihes o direito de atuarem como sujeitos ativos na sociedade.

Sant'Ana (1988) critica severamente o papel dos especialistas que emitem laudos incapacitantes sobre os indivíduos, fortalecendo o poder institucional sobre a potencialidade humana. Diz ele que toda uma equipe de técnicos, com instrumento de validade duvidosa, emite laudos cuja função é 
configurar o rótulo de deficiente, classificar e segregar os desviantes. (MARQUES et al., 2009, p. 92).

Diante da visão reducionista projetada nos sujeitos desviantes, instaurase uma perspectiva incapacitante, justificando-se a sua segregação dos espaços institucionais como medida de "proteção", já que não são suficientemente capazes de se sobressaírem no seio da sociedade. "Nessa perspectiva reside a eficácia da institucionalização do desvio: retirar os desviantes do convívio social e produzir uma imagem negativa sobre eles, atuando no nível simbólico de suas supostas e necessárias limitações" (MARQUES et al., 2009, p. 89).

A escola, na condição de espaço que dialoga com diversos setores, pode funcionar como um vetor propiciador da inclusão nos diferentes âmbitos sociais. Desse modo, é pertinente o questionamento: como utilizar a escola como elemento promotor da inclusão se essa escola não congrega as diferenças? Como fomentar a inclusão se o aluno público-alvo da educação especial estuda em espaços separados, sendo privado de um ambiente heterogêneo? Como se inserir nos distintos ambientes inclusivos se o educando não aprendeu a interagir em meio a um contexto inclusivo? Diante de tais questionamentos, Tomasini (1998) destaca a importância da ampliação da participação da pessoa com deficiência, entre outras diferenças, em múltiplos espaços:

Tratar da cidadania de indivíduos com diferenças significa ter no horizonte a ampliação de seus espaços de participação cultural, política e econômica, significa mobilizar suas potencialidades intelectuais, e isso me parece difícil de se concretizar nos ambientes segregados das instituições. Embora considerando a seriedade e as boas intenções de seus profissionais, a existência do espaço institucional especial é contraditoriamente uma espécie de negação da cidadania desses indivíduos. O sujeito constrói-se nas relações sociais e de produção mais ampla e não à margem delas. (TOMASINI In BIANCHETTI \& FREIRE, 1998, p. 126).

Diante da discussão sobre os processos de segregação por meio da institucionalização dos "sujeitos desviantes", o debate sobre a inclusão ganha força quando observamos os princípios dispostos pelos autores da chamada Psicologia histórico-cultural soviética. A esse respeito, podemos compreender 
que a aprendizagem e o desenvolvimento humanos não podem se processar em outro espaço senão em meio aos tecidos que compõem a rede social, considerando-se a natureza essencialmente social dos seres humanos. Segundo Vygotsky (1983), é nas relações sociais, nos espaços de coletividade, que se criam as condições necessárias ao desenvolvimento das funções mentais superiores. Aliás, o próprio psiquismo humano é uma construção de natureza social.

Das relações que emergem em meio ao convívio social se criam as condições ideais para a construção de conhecimentos. É mediante o intercâmbio entre as múltiplas visões, a troca de experiências, diálogos, pontos e contrapontos, consensos e contradições, oriundos da heterogeneidade presente no ambiente, que os saberes são construídos e desconstruídos, num constante apagar e acender, num dinamismo que move e transforma os saberes humanos.

A seguir, apresentaremos as discussões referentes ao processo histórico de escolarização das pessoas com deficiência no Brasil, materializado por meio do que poderíamos chamar de apartheid institucional. Prosseguiremos com algumas aproximações teóricas, por meio da obra de Vygotsky, no que tange ao processo de internalização cultural dos alunos com deficiência e da escola como lócus privilegiado para a transmissão dos saberes historicamente sistematizados pela humanidade. Tais aspectos apontam para a inclusão escolar como possibilidade de ampliação e modificação do sujeito por meio das trocas coletivas.

\section{O surgimento das instituições especializadas: um breve olhar sobre 0 processo histórico}

A dificuldade da sociedade em lidar com as diferenças é forte no Brasil, o que é expresso historicamente de vários modos, inclusive nas formas da lei. Se atentarmos para a Constituição de 1824 , em seu Título II, artigo $8^{\circ}$, inciso I, perceberemos uma tentativa de proteger a sociedade do adulto com deficiência, quando priva do direito político as pessoas com "incapacidades físicas ou morais". Entretanto, o atendimento escolar ao público com deficiência 
física se iniciou ainda no Brasil Colônia, com a criação de uma instituição especializada, de iniciativa privada, no estado de São Paulo, ligada à Santa Casa de Misericórdia, no ano de 1600 (JANNUZZI, 1992).

Mais de dois séculos após a criação da primeira instituição especializada voltada para a escolarização de pessoas com deficiência física, uma nova tentativa veio à tona em 1835 , a partir de um projeto de autoria do deputado Cornélio de França. Esse projeto previa a criação do cargo de professor primário especializado para o ensino de surdos tanto na capital, Rio de Janeiro, quanto nas demais províncias. A iniciativa não logrou êxito, resultando em seu arquivamento (JANNUZZI, 1992).

Pode-se dizer, então, que somente em 1854 se daria origem a uma ação mais efetiva do Governo Central com o apoio de outros atores que se aliaram à causa para a criação do Imperial Instituto dos Meninos Cegos. De acordo com Guerreiro (1976), o cego Álvares de Azevedo se destacou nessa luta, pois, ao retornar da França em 1851, onde realizou seus estudos no Instituto dos Jovens Cegos de Paris, dedicou-se à causa dos cegos brasileiros, que se encontravam esquecidos. Após traduzir e publicar o livro de J. Dondet - $A$ história do Instituto dos Meninos Cegos de Paris -, ganhou o apoio do médico do imperador, José Francisco Sigaud, que era pai de uma menina cega, e do conselheiro do monarca, Luiz Pereira do Couto Ferraz, que, por sua vez, encaminhou o projeto que deu origem à referida instituição, no ano de 1854.

Dois anos depois da criação do Imperial Instituto dos Meninos Cegos, foi criado o então Instituto dos Surdos-Mudos (1856). Ernesto Hüet, juntamente com seu irmão, conseguiu levantar o instituto voltado para a educação de crianças surdas, com o apoio do governo de Dom Pedro II, instituição que passou a se chamar posteriormente de Instituto Nacional de Educação dos Surdos.

Nos relatos de Jannuzzi (1992), o alcance dessas duas instituições (Imperial Instituto dos Meninos Cegos e Imperial Instituto dos Surdos-Mudos), no tocante ao atendimento de seu público-alvo, era bastante restrito. Basta dizer que em 1874 eram atendidos apenas 35 alunos cegos e 17 surdos, em uma população que era de 15.848 cegos e 11.595 surdos no ano de 1872 . 
Muito embora a atenção escolar a esse segmento da população fosse precária, o surgimento desses institutos especializados teria contribuído com a discussão que levou o imperador a convocar o I Congresso de Instrução Pública, aos 12 de dezembro de 1882, realizado no ano de 1883. Entre os temas abordados no congresso, estariam: sugestões para o currículo e formação de professores de surdos e cegos. Apesar da iniciativa, a escolarização das pessoas com deficiência ainda não compunha o quadro de prioridades do Governo Central; basta dizer que ele se esquivou de gastos decorrentes desse processo, ficando sob responsabilidade das províncias.

Segundo Jannuzzi (1992), Magalhães (1913) e Ribeiro (1976), no final do Império, se a educação das camadas populares era esquecida, muito mais a de pessoas com deficiência intelectual. Desse modo, encontramos apenas duas instituições voltadas para o atendimento médico e pedagógico dessa parcela da população, a saber: um espaço localizado nas dependências do Hospital Juliano Moreira, em Salvador, Bahia, que data de 1874, e o outro, Escola México, criado em 1887, localizado no Rio de Janeiro, sendo que essa instituição estendia seu atendimento a pessoas com deficiência física e visual.

Como se pode constatar nos estudos de Jannuzzi (1992) e Magalhães (1913), os médicos tiveram uma participação determinante para o processo de atendimento e escolarização das pessoas com deficiência intelectual no Brasil. Logo, partiu desses profissionais a iniciativa de criar espaços escolares ligados a hospitais psiquiátricos, por compreenderem a importância da pedagogia no atendimento a crianças na época classificadas com grave comprometimento mental e social. Inicialmente essas crianças eram mantidas nesses espaços de isolamento social juntamente com adultos que então apresentavam quadro clínico de "loucura". Como exemplo disso, encontramos a criação do Pavilhão Bourneville, em 1905, anexo ao Hospício da Praia Vermelha, na cidade do Rio de Janeiro, fundado por iniciativa dos médicos Juliano Moreira e Fernando Figueira. Tal empreendimento surgiu a partir de denúncias de uma comissão instaurada para investigar o estado em que se encontravam os então "alienados" presentes no Hospício Nacional e na Colônia da llha do Governador. 
De acordo com os relatos de Magalhães (1913), a comissão era composta pelos médicos Carlos Fernando Eira, Antônio Teixeira e Egídio de Salles Guerra e pelo farmacêutico M. F. da Silva Araújo. Era grande o desapontamento desses profissionais ao visualizarem crianças passeando em meio aos corredores do hospício ao lado de adultos com graves quadros de transtorno, expostas até mesmo a episódios de nudez.

Após a constatação, a comissão se reportou ao então ministro da Justiça para expor a preocupante situação das crianças, que dividiam o mesmo espaço com adultos, sujeitas a presenciarem até mesmo obscenidades. Desse modo, indicou-se a construção de um pavilhão infantil, anexo ao hospício, onde seriam realizadas as intervenções médicas e educativas como parte do tratamento, acreditando-se que desse modo haveria condições adequadas para que apresentassem melhoras. Com a iniciativa, deu-se origem às orientações pedagógicas concomitantemente ao atendimento clínico (JANNUZZI, 1992).

De acordo com a pesquisa de Müller (1998), o tratamento oferecido a essas crianças se dava inicialmente com a organização do espaço, em seguida eram definidas as intervenções terapêuticas. As crianças eram agrupadas mediante uma ferrenha classificação, que começava pelo sexo, sendo depois separadas em três grupos, segundo o quadro de deficiência em que eram enquadradas:

"O primeiro era composto por crianças na época denominadas de idiotas, cretinas, epiléticas ou não, mas 'inválidas', o segundo por crianças idiotas, cretinas ou não, mas 'válidas', e, o terceiro por crianças apropriadas, válidas, imbecis, retardadas, instáveis, perversas, epiléticas e histéricas ou não".

O elenco de atividades oferecidas no atendimento foi formulado sob uma óptica classificatória e estigmatizante, ou seja, a oferta escolar se organizava de modo a segregar todos aqueles que se desviavam do padrão de normalidade e se dividia de acordo com escalas previamente demarcadas, a partir do que se estipulava como "normal".

[...] Para o 'idiota válido' a pequena escola, para o 'inválido', o tratamento reabilitador e higiênico, para os adolescentes, as oficinas, para os demais a grande escola. Essa forma de 
organização do espaço e do tempo das crianças garantia o processo disciplinar, onde a criança era todo o tempo vigiada e controlada, numa junção perfeita entre o regime hospitalar classificatório, compondo um quadro geral e perfeitamente visível e sistematizado de uniformidades (MÜLLER, 1998, p. 85).

O senso de vigilância e controle estava presente no olhar e nas práticas do Estado no tocante ao tratamento das crianças com algum tipo de "desvio" em relação ao padrão normativo. O próprio diagnóstico era realizado pelos médicos peritos da polícia, que, após avaliação, encaminhavam as crianças ao internamento. No formulário de encaminhamento estava disposto que a delegacia deveria ser informada nos casos de alta ou eventual saída da criança. Isso demonstra a relação estabelecida entre deficiência e periculosidade, tendo como base para as internações as prescritivas policiais, justificando tais práticas através de supostos riscos morais à ordem pública (MÜLLER, 1998).

$\mathrm{Na}$ perspectiva foucaultiana, tais iniciativas atendiam ao discurso elaborado dentro da lógica da sociedade disciplinar, que tinha como objetivo o controle social, interferindo nas ações dos indivíduos e os impedindo de agir contra a ordem estabelecida. As instituições, por sua vez, apropriavam-se desse discurso, justificando suas práticas de reclusão, que tinham por objetivo vigiar e corrigir o sujeito. Dentre os mecanismos de controle, estão: a polícia responsável pela vigilância - e o hospício - responsável pela correção (FOUCAULT, 1996).

O atendimento institucional estava ligado a uma espécie de correção ou reparo moral, segundo o qual a pessoa era isolada e tratada mediante técnicas terapêuticas e pedagógicas, a fim de que essas crianças "anormais" se tornassem lucrativas para a sociedade de consumo, tornando-se elas mesmas responsáveis por sua própria manutenção. Cabia ao médico, mediante sua classificação clínica, apontar em quais crianças se poderia investir e quais deveriam ser abandonadas. Assim se travava o destino desses meninos (MÜLLER, 1998).

As manifestações "desviantes" são ameaçadoras da ordem estabelecida, portanto a anormalidade era tida como um risco moral à 
segurança, por isso a necessidade de disciplinar o indivíduo para que atingisse minimamente o padrão de normalidade. Como estratégia, estruturou-se um método médico-pedagógico a ser desenvolvido nas instituições hospitalares, numa perspectiva educativa em que a "[...] internação era parte do tratamento e tinha como objetivo a correção, o ajustamento social e a adequação às normas sociais e onde também a criança poderia melhorar espontaneamente, evitando futuros prejuízos econômicos e sociais ao Estado" (MÜLLER, 1998, p. 92).

De acordo com Müller (1998), inicialmente os objetivos perseguidos se voltavam para a apropriação de uma socialização adequada e para o desenvolvimento das atividades da vida diária. Em seguida, era realizado o que se chamava de ensino dos sentidos, que consistia na estimulação dos sentidos (estimulação visual, auditiva, gustativa, sinestésica) numa perspectiva funcional. Posteriormente se trabalhava o condicionamento de uma rotina, com o intuito de minimizar os desvios de conduta.

De acordo com Foucault (1998), a lógica da sociedade disciplinar se volta para a manutenção da ordem imposta, para o domínio e manutenção das forças que operam no poder. Tais forças atuam no sentido de neutralizar a ação do sujeito para que não ameace a ordem estabelecida. Tal sociedade tem como instrumento as instituições segregadoras, que têm por funções primordiais: vigiar e punir os indivíduos que não se enquadram na ordem em vigor.

Dentre os elementos que compõem esse aparato, destacamos a polícia, que tem a função de vigiar, e os internatos, que servem como aparelhos corretivos. Toda essa estrutura era referendada por agentes estratégicos, como: os médicos, que classificavam através de seus laudos; os juízes, que faziam uso das leis para assumirem o controle legal das vidas; e os professores, que eram responsáveis pelo "adestramento" e disciplinamento (MÜLLER, 2005).

Estudos realizados por Müller (2005) apontaram que Getúlio Vargas criou a Inspetoria Geral do Ensino Emendativo por meio do Decreto $\mathrm{n}^{\circ} 24.794$, aos 14 de julho de 1934. Sua intenção era agrupar as instituições que atendiam a crianças na época caracterizadas de anormais nas áreas do caráter, 
psíquica, física e moral. O intuito maior era a unificação institucional para a reclusão de crianças consideradas inúteis, anormais ou perigosas à sociedade. Contudo, seu plano não logrou êxito, pois as instituições existentes estavam ligadas a ministérios diferentes e, portanto, atendiam a interesses políticos distintos, impossibilitando, assim, a sua junção.

A incessante busca pela normalização do sujeito se voltava tanto para um viés de controle do Estado sobre a vida do indivíduo como para uma questão econômica, dado que havia uma preocupação com relação aos gastos que se tinha com os desvalidos. Assim,

\begin{abstract}
"[...] este esquadrinhamento era parte integrante do processo de normalização. Percebe-se a compreensão do internamento como processo necessário para que a criança se curasse, regenerasse e tornasse um sujeito produtivo, podendo então devolver ao Estado e à sociedade o que com ela fora gasto" (MÜLLER, 2005, p. 8).
\end{abstract}

Aqueles em que as técnicas psiquiátricas não surtiam efeito eram encaminhados para um processo educativo voltado apenas para a aquisição de conteúdos funcionais, também chamados de atividades da vida diária, em que se pretendia aproximá-los do padrão socialmente estabelecido. "Ao atingirem a maioridade, realizava-se a permuta da ala infantil para a dos adultos, onde eram entregues ao esquecimento até mesmo institucional” (MÜLLER, 2005, p. 9).

Segundo Marques et al. (2009), no contexto institucional o indivíduo perde suas características individuais e recebe o estigma do segmento ao qual pertence; em outros termos, envolta pelas paredes da instituição, a pessoa perde suas particularidades como sujeito desejante, possuidor de capacidades, e ganha um estereótipo próprio do grupo ao qual pertence. Assim, vê-se um aluno com deficiência intelectual, por exemplo, como igual a todos os outros, desprovido de suas características individuais.

Ao refletirmos sobre os benefícios da institucionalização da pessoa com deficiência, percebemos que suas "vantagens" são voltadas para a sociedade dos "normais", que se redime, num olhar beneficente, do peso da culpa pela segregação histórica. Do ponto de vista dos institucionalizados, tem-se um prejuízo pela privação cultural a que são submetidos, uma vez que as 
aprendizagens e aquisições das funções superiores são mediadas a partir dos processos coletivos.

De acordo com Marques et al. (2009), Vygotsky tece uma crítica acerca dos profissionais especialistas que se centram nos exames e apontam tão somente para as limitações do indivíduo. A partir da realização de testes padronizados, esses educandos são categorizados e encaminhados às escolas e demais serviços especializados, em que muitos permanecem isolados ao longo de suas vidas. A visão de Foucault sobre essa acepção médica "patologizante" vem em concordância com o parecer de Vygotsky, quando fala dos exames clínicos que classificam a pessoa, conforme apontam Marques et al. (2009, p. 83):

O exame assumiu um importante papel no processo de isolamento dessas pessoas em diferentes instituições. Foucault (1999, p. 107) destaca que o exame é a vigilância permanente, classificatória, que permite distribuir os indivíduos, julgá-los, medi-los, localizá-los, e, por conseguinte, utilizá-los ao máximo.

Revestidos de um biopoder ${ }^{1}$ esses especialistas caracterizam e enquadram os sujeitos desviantes tendo como parâmetro aquilo que é convencionalmente estabelecido como normal. Assim, dentro dessa relação de poder e dominação, estes grupos sofrem sanções sociais, tais como: subempregos e à negação do acesso a diferentes espaços à população negra; abandono e improdutividade aos idosos; reclusão por meio da institucionalização às pessoas com deficiência, transtornos psiquiátricos e outras inadequações consideradas "desvio de conduta".

A seguir, discutiremos o processo de escolarização das pessoas com deficiência e a centralidade da escola comum que além de um direito se constitui um espaço privilegiado para a aquisição das habilidades humanas por meio da apropriação da cultura e dos saberes historicamente sistematizados pela humanidade.

\footnotetext{
${ }^{1}$ Biopoder é um termo elaborado pelo filósofo francês Michel Foucault para referir-se à prática dos Estados modernos e seus processos de regulação dos que a ele estão sujeitos por meio de uma "de técnicas numerosas e diversas para obter a subjugação dos corpos e o controle de populações".
} 


\section{Vygotsky e a escolarização de alunos com deficiência}

Mediante a conjuntura vigente, as pessoas com deficiência, assim como qualquer grupo não hegemônico, precisam ser vistas como cidadãos de direito, desvencilhando-se da visão assistencialista à qual foram submetidas durante muito tempo. Essa visão as deixa em segundo plano, como meros coadjuvantes, ainda que sob a alegação de compensação - segregação. Assim, é preciso que haja a apropriação dos mecanismos que favoreçam a autonomia dessas pessoas, a fim de que se apropriem das ferramentas necessárias à construção de sua cidadania (SASSAKI, 2003).

Um dos maiores instrumentos para a equiparação de oportunidades é sem dúvidas a educação. É por meio dela que o homem se emancipa, que adquire a consciência de si e do mundo que o cerca, o que se constitui ponto de partida para as conquistas por ele aspiradas (FREIRE, 1999).

Poulin (2010, p. 37) destaca a escola como a grande propulsora do processo colaborativo, pois é mediante as práticas educativas que se constroem relações de mutualidade, pautadas em valores e práticas cooperativas, que permitem a elaboração de um modelo social equânime:

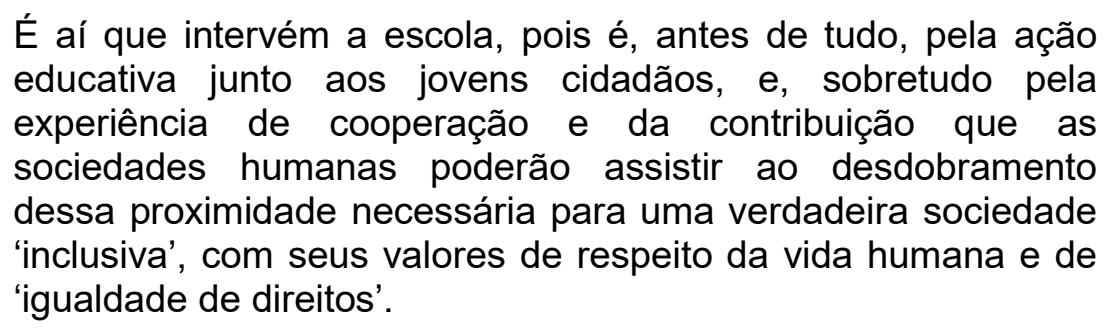

Entretanto, a escola, como aparelho ideológico de um sistema desigual, reproduz a lógica que perpetua a estrutura de poder e dominação existentes. Tal estrutura inclui os seres humanos de forma injusta a partir de hierarquias centradas na desigualdade, marginalizando e estabelecendo padrões impermeáveis a todos os que nela não se enquadram (POULIN, 2010).

A educação é um setor que se insere em meio a uma sociedade desigual, em que alguns possuem bens em excesso e outros detêm apenas a força de trabalho. Nessa ordem se constituem exploradores e explorados, ricos e pobres, dominadores e dominados, todos incluídos em meio a essa lógica. 
Por razão desse contexto, faz-se necessária a luta por uma sociedade que inclua de maneira mais justa os excluídos (ROSSETTO et al., 2006).

Vivemos em uma sociedade estruturada para atender a um tipo de padrão de seres humanos, uma vez que se busca uniformizar, no processo de "massificação" do homem, suas características, com vistas a atender a uma lógica de mercado, objetivando-se perpetuar a estrutura de poder existente.

Dentro desse contexto, a deficiência e demais diferenças presentes no ser humano desestabilizam uma lógica voltada para um padrão de normalidade culturalmente estabelecido, o que impede sua inserção direta dentro desse universo cultural como ocorre com os ditos normais.

O defeito, ao criar um desvio do tipo humano biológico estável do homem, ao provar a perda das funções, a insuficiência ou a deterioração dos órgãos, a reestruturação, mais ou menos substancial, de todo o desenvolvimento sobre novas bases, segundo o novo tipo, perturba, logicamente, o curso normal do processo de enraizamento da criança à cultura, já que a cultura está acomodada a uma pessoa normal, típica, está adaptada à sua constituição, e o desenvolvimento atípico está condicionado pelo defeito não pode se enraizar direta e imediatamente na cultura, como ocorre com a criança normal. (VYGOTSKY, 1983, p. 27, tradução nossa²).

No entanto, o processo de desenvolvimento da criança, em suas múltiplas dimensões, ocorre fundamentalmente a partir de sua inserção no contexto sociocultural. É na relação de troca que se viabiliza dialogicamente a aprendizagem e o desenvolvimento da pessoa.

Portanto, caso se questione de onde nascem, como se formam, de que modo se desenvolvem os processos superiores do pensamento infantil, devemos responder que surgem no processo de desenvolvimento social da criança por meio da transferência a si mesma das formas de colaboração

\footnotetext{
2 "El defecto, al crear una desviación del tipo humano biológico estable del hombre, al provocar la pérdida das funciones, la insuficiencia o deterioro de órganos, la reestructuración, más o menos sustancial, de todo el desarrollo sobre nuevas bases, según el nuevo tipo, perturba, lógicamente, el curso normal del proceso de arraigo del niño en la cultura, ya que la cultura está acomodada a una persona normal, típica, está adaptada a su constituición, y el desarrollo atípico condicionado por el defecto no puede arraigar directa e inmediatamente en la cultura, como sucede en el niño normal" (VYGOTSKY, 1983, p. 27).
} 
que a criança assimila durante a interação com o meio social que a rodeia. (VYGOTSKY, 1983, p. 219, tradução nossa ${ }^{3}$ ).

De modo contrário, se a criança é privada do convívio social, do contato com o outro, da construção coletiva, instala-se aí uma barreira para o pleno desenvolvimento da pessoa, comprometendo, desse modo, as funções psíquicas superiores, uma vez que tais funções têm como condição, para a sua maturação, as relações de mutualidade em meio a um contexto sociocultural.

O distanciamento da coletividade ou a dificuldade de desenvolvimento social, por sua vez, determina o desenvolvimento incompleto das funções psíquicas superiores, as quais, quando é normal o curso das coisas, surgem diretamente em relação com o desenvolvimento da atividade coletiva da criança. (VYGOTSKY, 1983, p. 223, tradução nossa ${ }^{4}$.

Em relação à aprendizagem e ao desenvolvimento do aluno com deficiência, a luta não é contra a deficiência, haja vista que esta se apresenta como condição natural do sujeito. Entretanto, a busca por sua inserção em um ambiente socioeducacional inclusivo favorece sobremaneira o desenvolvimento de suas funções superiores, viabilizando a sua aprendizagem e autonomia através das trocas ocorridas nas atividades coletivas. "[...] Assim como é praticamente inútil lutar contra o defeito e suas consequências diretas, é, ao contrário, legítima, frutífera e promissora a luta contra as dificuldades na atividade coletiva" (VYGOTSKY, 1983, p. 223, tradução nossa5).

No caso dos alunos surdos, por exemplo, Vygotsky (1983) afirma que a sua reclusão em ambientes isolados apenas para surdos prejudica o seu desenvolvimento, pois é no contexto social da coletividade que se constrói a

\footnotetext{
3 "Por tanto, si se pregunta de dónde nacen, cómo se forman, de qué modo se desarrollan los procesos superiores del pensamiento infantil, debemos responder que surgen en el proceso de desarrollo social del niño por medio de la traslación a sí mismo de las formas de colaboración que el niño asimila durante la interacción con el medio social que lo rodea" (VYGOTSKY, 1983, p. 219).

4 "[...] El apartamiento de la colectividad o la dificultad del desarrollo social, a su vez, determina el desarrollo incompleto de las funciones psíquicas superiores, las cuales, cuando es normal el curso de las cosas, surgen directamente en relación con el desarrollo de la actividad colectiva del niño" (VYGOTSKY, 1983, p. 223).

5 "Así como es prácticamente inútil luchar contra el defecto y sus consecuencias directas, es, a la inversa, legítima, fructífera y promisora la lucha contra las dificultades en la actividad colectiva" (VYGOTSKY, 1983, p. 223).
} 
linguagem, a partir da qual se socializam a aprendizagem e a educação voltada para a inclusão social.

[...] a exclusão da criança surda-muda da comunidade, seu confinamento exclusivamente ao ambiente de outras surdasmudas e a dolorosa alteração de sua comunicação e colaboração com os ouvintes. Todo o círculo é consequentemente composto de três momentos interligados. A educação social se apoia no desenvolvimento incompleto da linguagem, o que leva à exclusão da comunidade, e a exclusão da comunidade simultaneamente retarda a educação social e o desenvolvimento da linguagem. (VYGOTSKY, 1983, p. 232, tradução nossa6).

Destacam-se, desse modo, as contribuições coletivas entre alunos surdos e ouvintes mediante o emprego de uma linguagem acessível, que permita uma ampla compreensão entre os pares, haja vista que isso vem a ser essencial para a aprendizagem e o desenvolvimento de ambos.

Por isso o estudo da coletividade das crianças surdas-mudas, as possibilidades de uma colaboração coletiva com as crianças ouvintes, o uso máximo de todos os tipos de linguagem acessíveis à criança surda-muda, é uma condição necessária para a melhora profunda de sua educação. (VYGOTSKY, 1983, p. 233 , tradução nossa ${ }^{7}$ ).

Vygotsky (1983) ressalta a importância das interações da criança para o desenvolvimento de suas funções intelectuais superiores. Desse modo, o autor traz uma grande contribuição para a concepção de um ambiente escolar inclusivo, visto que é em meio ao trabalho coletivo que há a contribuição entre os pares, o que viabiliza a aprendizagem e o desenvolvimento da criança. Embora com ritmos e formas de aprendizagem peculiares, o desenvolvimento

\footnotetext{
6 "[...] la exclusión del niño sordomudo de la colectividad, su reclusión exclusivamente en el ambiente de los otros sordomudos y la penosa alteración de suy comunicación y colaboración con los oyentes. Todo el círculo está compuesto, por conseguiente, de tres momentos intervinculados entre si. La educación social se apoya en el desarrollo incompleto del lenguaje, este conduce a la exclusión de la colectividad, y la exclusión de la colectividad frena simultáneamente tanto la educación social como el desarrollo lingüístico" (VYGOTSKY, 1983, p. 232).

7 "[...] la exclusión del niño sordomudo de la colectividad, su reclusión exclusivamente en el ambiente de los otros sordomudos y la penosa alteración de suy comunicación y colaboración con los oyentes. Todo el círculo está compuesto, por conseguiente, de tres momentos intervinculados entre si. La educación social se apoya en el desarrollo incompleto del lenguaje, este conduce a la exclusión de la colectividad, y la exclusión de la colectividad frena simultáneamente tanto la educación social como el desarrollo lingüístico" (VYGOTSKY, 1983, p. 232).
} 
da criança com deficiência, por sua vez, assemelha-se ao das demais. Portanto, é na relação de troca, de parceria, que se torna real o conhecimento que está latente dentro do universo de possibilidades da criança.

A privação ou o isolamento da criança de um ambiente rico em diferenças inviabiliza seu desenvolvimento, Logo, Vygotsky (1983) destaca que a negação dos espaços coletivos vem a ser o verdadeiro fator impeditivo do desenvolvimento da criança com deficiência, uma vez que lutar contra a deficiência seria inútil, já que essa é uma particularidade natural da pessoa. Deve-se, assim, lutar pelo ingresso dos alunos com deficiência nos diferentes espaços sociais, cabendo destacar, entretanto, que a escola é a grande propulsora da inclusão em todas as suas dimensões.

É muito comum presenciarmos no cotidiano da escola cenas que demonstram como o aluno é culpabilizado por seu fracasso escolar, levando em consideração apenas seus aspectos cognitivos, refutando as possibilidades que emergem do contexto social em que a criança está imersa, bem como as situações que podem ser criadas pelo professor, na condição de mediador, para o favorecimento da aprendizagem do aluno, como nos mostram Figueiredo e Poulin (2008, p. 247) em seus estudos sobre os aspectos funcionais do desenvolvimento cognitivo de crianças com deficiência mental: "O desenvolvimento de estratégias de resolução de problemas depende algumas vezes das características cognitivas do sujeito e outras vezes dos suportes sociais e contextuais que lhes são oferecidos".

No entanto, é muito mais difícil quebrar as barreiras culturais do que as da deficiência, pois já se cristalizou no universo cultural a ideia de incapacidade da pessoa com deficiência. Por isso, Vygotsky (1983) revela a importância da quebra dos paradigmas culturais que impedem o acesso e a permanência das pessoas com deficiência nos diferentes espaços culturais, sociais e educacionais, dado que são esses espaços que viabilizam a possibilidade da aprendizagem e do desenvolvimento de todos os seres humanos.

Grandes foram as contribuições do pensamento sociointeracionista para os saberes e práticas nos campos da Psicologia e da Pedagogia, entre outros. Dentre os principais representantes dessa corrente, destaca-se Vygotsky, pela 
relevância dispensada ao processo educacional da criança, considerando sobretudo a escola como lugar privilegiado para a construção da aprendizagem e desenvolvimento da pessoa. De igual modo, o papel do "outro" na condição de mediador do processo de aprendizagem, fato que dá primazia à riqueza da heterogeneidade, das diferenças, para o enriquecimento das experiências de aprendizagem no ambiente escolar.

Os estudos de Vygotsky sobre crianças com deficiência, na época chamadas de crianças com "defeito", contribuíram sobremaneira para esse campo de conhecimento, ao qual o autor dedicou parte considerável de sua obra. Caminharemos com esse autor durante a pesquisa, à luz da teoria sociointeracionista, por entendermos que os processos não ocorrem isoladamente do contexto sócio-histórico, que o sujeito se desenvolve mediante um processo dialético em meio a uma realidade sociocultural em que ele a transforma ao mesmo tempo que é transformado.

Desse modo, entende-se que os termos que designam os fenômenos sociais sofrem a influência direta do contexto sócio-histórico em que se encontra o autor. Entretanto, mesmo fazendo uso do termo "defeito" para se referir às pessoas com deficiência, Vygotsky (1983) inova na concepção que tem desses sujeitos e rompe com a estrutura cultural que os condena a viver em espaços separados.

O processo educativo é compreendido por Vygotsky (1983) como o processo que, embora extrínseco ao sujeito, oferece-lhe os instrumentos a partir dos quais ele poderá operar tanto na realidade objetiva quanto na instância subjetiva, isso porque, por meio da apropriação da cultura, o ser humano consegue produzir os instrumentos que the possibilitarão transformar a natureza para garantir suas condições de existência. Do mesmo modo, há um trabalho interno que demanda a utilização de instrumentos mediadores por meio dos quais se torna possível operar o próprio pensamento, assim:

A educação, por sua vez, pode ser definida como o desenvolvimento artificial da criança. A educação é o domínio engenhoso dos processos naturais do desenvolvimento. A educação não apenas influi sobre uns ou outros processos do desenvolvimento, como também reestrutura, da maneira mais 
essencial, todas as funções da conduta. (VYGOTSKY, 1987, p. 187).

Por essa razão, a escola constitui-se um lócus privilegiado para o processo de desenvolvimento humano, uma vez que é o espaço em que são transmitidos os saberes historicamente sistematizados pela humanidade. $A$ apropriação desse conjunto de conhecimentos ou acervo cultural modifica o sujeito, pois the oferece os instrumentos que the possibilitarão superar as funções mentais elementares rumo às funções mentais superiores. Isso ocorre no instante em que o indivíduo passa a usar dos signos como instrumentos mediadores da ação do pensamento, superando a análise da realidade a partir da mera captação sensorial. A esse respeito, Baquero (1998, p. 76) afirma que:

[...] os processos de desenvolvimento consistem na apropriação de objetos, saberes, normas e instrumentos culturais em contextos de atividade conjunta socialmente definidos (família, escola, com seus diversos formatos de atividade). A 'educação' (aprendizagem em contextos de ensino com graus diversos de formalidade) possui um papel inerente (não meramente coadjuvante) aos processos de desenvolvimento. O desenvolvimento é, nestas condições, um processo artificial. E na medida em que a apropriação implica a interiorização progressiva de operações psicológicas originadas intersubjetivamente, e que tal processo pode ficar truncado ou incompleto, o desenvolvimento das formas mais avançadas do psiquismo resultará um processo contingente.

Problemas relacionados à formação dos professores e demais membros da escola, precariedade da estrutura física e de materiais da escola, entre outros, são dificuldades de ordem social que interferem na formação de todos os alunos, portanto não é um agravante na vida escolar apenas dos estudantes com deficiência. Tais entraves se interpõem no processo de aprendizagem da criança, impedindo-a de atingir níveis mais elevados de desenvolvimento. "Por acaso a enorme massa de crianças sadias da humanidade alcança tudo que eles poderiam e deveriam obter em sua estrutura psicofisiológica?" (VYGOTSKY, 1987, p. 87).

A teoria histórico-social trouxe à tona a importância vital das relações interpessoais para a formação do ser humano. Não se pode construir seres humanos fora das relações sociais. Segundo Vygotsky (1987), a pessoa é resultante de duas vertentes: uma natural e outra social. A partir dessa 
premissa, ele configura os campos genéticos no processo de evolução, sendo estes: a filogênese, que diz respeito à evolução da espécie humana; a ontogênese, que concerne ao caminho evolutivo do homem dentro da sua espécie; a sociogênese, que tem relação direta com o processo histórico dos grupos socioculturais em que esse homem está inserido; e a microgênese, que é inerente às experiências individuais de cada sujeito em meio a uma realidade sociocultural.

Assim, pode-se dizer que o processo filo e ontogenético é uma condicionante que atravessa o ser humano, de maneira involuntária. Entretanto, é o repertório sócio-histórico, em comunicação dialética com a pessoa, que a transforma em ser humano, ao mesmo tempo que essa realidade social também é transformada pelos seus indivíduos. O ser humano é, por assim dizer, sujeito em um contexto sócio-histórico, sendo este responsável pela viabilização da aprendizagem, por meio da transformação da linguagem, dos símbolos e dos signos, sem os quais se inviabilizaria o desenvolvimento humano. É, portanto, a aprendizagem que torna possível o desenvolvimento, isto é, a aprendizagem ocorre primeiro, sendo a partir dela que as estruturas mentais e orgânicas se transformam, resultando no desenvolvimento.

Não podemos fragmentar a pessoa, compreendendo e intervindo em seu desenvolvimento de modo a separá-la em segmentos orgânico, psicológico, social, etc. É necessário entendermos o ser humano globalmente, numa estrutura integrada. Desse modo, torna-se inviável dicotomizar o desenvolvimento do aluno público-alvo da educação especial. Se a aprendizagem torna possível o desenvolvimento, é inútil tentarmos estimular o desenvolvimento de pessoas com deficiência intelectual, por exemplo, sem investirmos em sua aprendizagem.

\section{Considerações Finais}

Partindo do objetivo de estudar o processo de escolarização de pessoas com deficiência no Brasil, à luz dos pressupostos teóricos presentes na obra de Lev Vygotsky, foi possível apreender a trajetória histórica de segregação 
desses indivíduos. Pudemos constatar que as pessoas com deficiência foram marginalizadas em função do padrão de normalidade que se convencionou na esteira da história, materializado em diferentes espacialidades e condicionantes culturais.

No entanto, o padrão de normalidade socialmente estabelecido, embora seja amalgamado ao sujeito e transmitido ideologicamente como atributo natural, é construído para garantir a supremacia de um grupo sobre outro, justificando, assim, os processos de opressão e dominação.

Logo, a construção da normalidade passa necessariamente por uma relação de poder que se liga diretamente ao modo de produção capitalista, que demanda um determinado tipo de homem e de mulher para atender às necessidades do modo de produção capitalista. Ou seja, o próprio perfil de normalidade é elaborado sob a óptica da economia, que objetifica o ser humano em função do acúmulo do capital.

Nessa perspectiva, as instituições especializadas surgem como espécies de "guardiãs" da ordem social, ameaçada pela presença de sujeitos desviantes que subvertem a ordem e afrontam a perpetuação do status quo. Essas instituições são mecanismos disciplinares que resguardam os ditos normais do convívio com aqueles que destoam da identidade hegemônica. Do mesmo modo, funciona como dispositivo de coação e punição exemplar com o intuito de garantir o controle e a continuidade do sistema social existente.

No que concerne aos apontamentos de Vygotsky, destacamos a relevância das mediações sociais para o processo de superação da base biológica em que se assenta o desenvolvimento humano, isso porque organicamente o homem não traz consigo as condições de existência, necessitando, pois, construir os meios para a sua sobrevivência. Nesse movimento, acumula-se um conjunto de conhecimentos que são transmitidos ao longo da história e internalizados pelos sujeitos.

Sendo o homem um ser social, fazem-se necessárias as condições para que haja a construção de sua natureza cultural. Nos estudos da defectologia, Vygotsky (1983) indica que o desenvolvimento das funções mentais superiores ocorre por meio das trocas coletivas, pois é na coletividade que os homens se 
fazem homens. Assim, compreende-se que a escola comum inclusiva ganha destaque no processo de transmissão dos saberes historicamente sistematizados pela humanizada, e de apropriação cultural. Desse modo, quanto mais diversificado for esse ambiente em suas interações, mais ricas serão as trocas e as possibilidades de desenvolvimento das aquisições intelectivas e sociais do sujeito.

Se, pois, o desenvolvimento não se constitui por vias exclusivamente biológicas, a superação de tais componentes elementares ocorre por intermédio da relação dialética entre sujeito e meio ou ainda entre organismo e meio, portanto destaca-se o caráter fulcral da inclusão em seu sentido mais amplo, pois, sendo o homem síntese de múltiplas determinações, privá-lo das interações sociais significa negar-lhe a possibilidade de hominização.

\section{Referências}

BAQUERO, R. Vygotsky e a aprendizagem escolar. Porto Alegre, Artes Médicas, 1998.

BIANCHETTI, L. \& FREIRE, I. M., Um olhar sobre a diferença: interação trabalho e cidadania, Campinas, Papirus, 1998.

BRASIL, Política Nacional de Educação Especial na Perspectiva da Educação Inclusiva, Brasília: MEC, 2007.

POULIN, J. R. Quando a escola permite a contribuição no contexto das diferenças. In: FIGUEIREDO, R. V. et al. Novas luzes sobre a inclusão escolar. Fortaleza, Edições UFC, 2010.

FOUCAULT, M. (1996). A ordem do discurso. São Paulo: Edições Loyola.

FOUCAULT, M. Os anormais. São Paulo, Martins Fontes, 1999.

FREIRE, P. Educação como Prática da Liberdade. Rio de janeiro, Paz e Terra, 1999.

GUERREIRO, Lizair de Moraes Guarino (1976). A iniciativa privada no atendimento ao excepcional. In: OEA, Seminário sobre o Planejamento ao Atendimento aos Excepcionais. Foz do Iguaçu, 9 a 13 set. 43p.

JANNUZZI, G., A luta pela educação do deficiente mental no Brasil, Autores Associados, Campinas, 1992, 2ed.

MAGALHÃES, Basílio de., Tratamento e educação das crianças anormais de inteligência: contribuições para o estudo desse complexo problema 
científico e social, cuja solução urgentemente reclamam, - a bem da infância de agora e das gerações vindouras, - os mais elevados interesses materiais, intelectuais e morais da prática brasileira. Rio de Janeiro, Tip. Do Jornal do Comércio de Rodrigues S. C., 1913.

MARQUES, C. A. \& MARQUES, L. P. et. al. Da exclusão à inclusão: (re)construindo significados à luz dos pensamentos de Vygotsky, Paulo Freire e Michel Foucault. Juiz de Fora, UFJF, 2009.

MÜLLER, T. M. P., A primeira escola especial para "creanças anormaes" no Distrito Federal - O Pavilhão Bourneville do Hospício Nacional dos Alienados (1903-1920): uma leitura foucaultiana. Dissertação de Mestrado, UERJ, 1998.

PILETTI, C.: PILETTI, N. História da educação. São Paulo: Ática, 1990.

RIBEIRO, M. L. S. História da educação brasileira: a organização escolar. 3. ed. São Paulo: Moraes, 1981.

ROSSETTO, E. et. al, Programa Institucional de Ações Relativas às Pessoas com Necessidades Especiais - PEE. Pessoas com deficiência: aspectos teóricos e práticos. Edunioeste, Cascavel, 2006a.

SANT'ANA, G. C. O excepcional e a excepcionalidade da ordem sóciocultural, Fórum Educacional, Rio de Janeiro, FGV, 1988.

SASSAKI, Romeu Kazumi. Inclusão: Construindo uma sociedade para todos. 5.ed. Rio de Janeiro: WVA, 2003.

TOMASINI, M. E. A., Expatriação social e a segregação institucional da diferença: reflexões. In: BIANCHETTI, L.; FREIRE, I. M., Um olhar sobre a diferença: interação, trabalho e cidadania, Campinas, Papirus, 1998.

VYGOTSKY, L. S. Fundamentos de Defectologia, Madrid, Rógar, 1983.

VYGOTSKY, L. S. Historia del desarrollo de las funciones psicológicas superiores. La Havana, Científico-técnica, 1987.

\section{Sobre os autores}

\section{Francélio Ângelo de Oliveira}

oliveira.angelo@ifce.edu.br

Doutorando em Educação pela Universidade Federal do Ceará, mestre em Educação-UFC, especialista em Educação Inclusiva-UECE, especialista em Psicomotricidade Clínica-UFC, graduado em Licenciatura em PedagogiaFAIBRA, graduado em Licenciatura Plena em Ciências da Religião-UVA e graduado em Tecnologia em Hotelaria-IFCE. Professor efetivo do Instituto Federal de Educação, Ciência e Tecnologia do Ceará-IFCE/Campus Acaraú. Membro da Associação Brasileira dos Pesquisadores em Educação Especial e da Sociedade Brasileira de Psicomotricidade-Capítulo Ceará. Atua 
principalmente nos seguintes temas: inclusão escolar, Atendimento Educacional Especializado, relações de gênero e diversidade sexual.

\section{Adriana Leite Limaverde Gomes}

adrianalimaverde@ufc.br

Graduada em Pedagogia pela Universidade Estadual do Ceará (1983), Especialista em Psicomotricidade pela Unifor (1991), Mestre em Educação pela Universidade Federal do Ceará (2001) e Doutora em Educação pela Universidade Federal do Ceará (2006). Professora Associado I da Universidade Federal do Ceará/Faculdade de Educação/Departamento de Teoria e Prática de Ensino das disciplinas da área de Didática, Estágio no Ensino Fundamental e Ensino da Língua portuguesa. Coordenadora do PIBID/Subprojeto de Educação Inclusiva durante o período de agosto/2012 a fevereiro/2018. Coordenadora do Programa de Residência Pedagógica/Subprojeto de Pedagogia durante o período de agosto/2018 a julho/2019. Coordenadora na Universidade Federal do Ceará do Projeto Interinstitucional Arca Alfabetização com Recursos abertos de Comunicação Alternativa a partir de métodos e tecnologias inovadores aplicados à crianças com deficiência intelectual e/ou TEA, realizado em parceria com a Universidade Federal do Rio Grande do Sul e Universidade Federal de Pernambuco, com financiamento da CAPES. Professora do Programa de Pós-graduação em Educação Brasileira da Universidade Federal do Ceará, atuando na Linha de Pesquisa Linguagens e Práticas Educativas, orientando dissertações e teses nos eixos de estudos da linguagem: oralidade, leitura e escrita, escola e educação inclusiva. Líder do Grupo de Pesquisa LER (Linguagem Escrita Revisitada) - CNPQ. Parecerista Ad-hoc do $\mathrm{CNPq}$ e Capes. Pesquisadora na área de Educação atuando principalmente nos seguintes temas: Alfabetização e Letramento, Aquisição e Desenvolvimento da Língua Escrita, Dificuldades de Aprendizagem da leitura e da escrita, Educação Especial na perspectiva da Educação Inclusiva, Práticas Pedagógicas no Contexto das Diferenças, Formação de Professores no Contexto da Sala de Aula Inclusiva, Aprendizagem da Leitura e da Escrita do Aluno com Deficiência Intelectual, Atendimento Educacional Especializado AEE, Uso de softwares na comunicação escrita de alunos com deficiência intelectual 